\title{
THE METRIC DIMENSION OF A GRAPH COMPOSITION PRODUCTS WITH STAR
}

\author{
S.W. Saputro ${ }^{1}$, D. Suprijanto ${ }^{2}$, E.T. Baskoro ${ }^{3}$, And A.N.M. \\ SALMAN ${ }^{4}$ \\ ${ }^{1}$ Combinatorial Mathematics Research Group \\ Faculty of Mathematics and Natural Sciences \\ Institut Teknologi Bandung \\ Jl.Ganesa 10 Bandung 40132 Indonesia \\ suhadi@math.itb.ac.id \\ ${ }^{2}$ Combinatorial Mathematics Research Group \\ Faculty of Mathematics and Natural Sciences \\ Institut Teknologi Bandung \\ Jl.Ganesa 10 Bandung 40132 Indonesia \\ djoko@math.itb.ac.id \\ ${ }^{3}$ Combinatorial Mathematics Research Group \\ Faculty of Mathematics and Natural Sciences \\ Institut Teknologi Bandung \\ Jl.Ganesa 10 Bandung 40132 Indonesia \\ ebaskoro@math.itb.ac.id \\ ${ }^{4}$ Combinatorial Mathematics Research Group \\ Faculty of Mathematics and Natural Sciences \\ Institut Teknologi Bandung \\ Jl.Ganesa 10 Bandung 40132 Indonesia \\ msalman@math.itb.ac.id
}

\begin{abstract}
A set of vertices $W$ resolves a graph $G$ if every vertex is uniquely determined by its coordinate of distances to the vertices in $W$. The minimum cardinality of a resolving set of $G$ is called the metric dimension of $G$. In this paper, we consider a graph which is obtained by the composition product between two graphs. The composition product of graphs $G$ and $H$, denoted by $G[H]$, is the graph with vertex set $V(G) \times V(H)=\{(a, v) \mid a \in V(G) ; v \in V(H)\}$, where $(a, v)$ adjacent with $(b, w)$ whenever $a b \in E(G)$, or $a=b$ and $v w \in E(H)$. We give a general bound of the metric dimension of a composition product of any connected graph $G$ and a star. We also show that the bound is sharp.
\end{abstract}

Key words: Basis, composition product, metric dimension, resolving set, star.

2000 Mathematics Subject Classification: 05C12, 05C76.

Received: 25-10-2011, revised: 13-07-2012, accepted: 24-07-2012. 
Abstrak. Himpunan titik $W$ membedakan graf $G$ jika setiap titik ditentukan secara
tunggal oleh koordinat jaraknya ke titik-titik di $W$. Kardinalitas minimum dari
sebuah himpunan pembeda dari $G$ disebut dimensi metrik of $G$. Pada paper
ini, kami meneliti graf yang diperoleh dari hasil kali komposisi antara dua graf.
The Hasil kali komposisi dari graf $G$ dan $H$, dinyatakan dengan $G[H]$, adalah graf
dengan himpunan titik $V(G) \times V(H)=\{(a, v) \mid a \in V(G) ; v \in V(H)\}$, dengan $(a, v)$
bertetangga dengan $(b, w)$ bilamana $a b \in E(G)$, atau $a=b$ dan $v w \in E(H)$. Kami
menunjukkan sebuah batas umum dari dimensi metrik hasil kali komposisi dari
sebarang graf terhubung $G$ dengan graf bintang. Kami juga menunjukkan bahwa
batas tersebut tajam.
Kata kunci: Basis, hasil kali komposisi, dimensi metrik, himpunan pembeda, graf Kata kuntang.

\section{Introduction}

Throughout this paper, all graphs are finite, simple, and connected. Let $G$ be a graph. We denote by $V_{G}$ or $V$ the vertex set of $G$, and $E_{G}$ or $E$ the edge set of $G$.

The metric dimension were first studied by Harary and Melter [8], and independently by Slater $[16,17]$. The basic parameter for this topic is the distance of two vertices in a graph. For any two distinct vertices $u, v \in V(G)$, the distance $d_{G}(u, v)$ between $u$ and $v$ is the length of a shortest $(u, v)$-path in $G$. In particular, if $d_{G}(u, w) \neq d_{G}(v, w)$, then we say that $u$ and $v$ are resolved by $w$. For an ordered $k$-tuple $W=\left\{w_{1}, w_{2}, \ldots, w_{k}\right\}$ of $V(G)$ and a vertex $v \in V(G)$, the representation of $v$ with respect to $W$ is the $k$-tuple $r(v \mid W)=\left(d_{G}\left(v, w_{1}\right), \ldots, d_{G}\left(v, w_{k}\right)\right)$. We call $W$ as a resolving set if $r(u \mid W) \neq r(v \mid W)$ for every two distinct vertices $u, v \in V(G)$. A resolving set of $G$ with minimum cardinality is called basis, and its cardinality is called metric dimension of $G$, and denoted by $\beta(G)$.

Trivially, if $G$ is a graph of order $n$, then $\beta(G) \leq n$, by taking all vertices of $G$ to be a resolving set. However, we may obtain a resolving set whose cardinality is less than $n$. Chartrand et al [5] showed that $\beta(G)=1$ if and only if $G \cong P_{n}$. Furthermore, they proved that $K_{n}$ is the only graph $G$ with $\beta(G)=n-1$. They also proved that $\beta(G)=n-2$ if and only if $G$ is $K_{r, s}$ for $r, s \geq 1, K_{r}+\overline{K_{s}}$ for $r \geq 1, s \geq 2$, or $K_{r}+\left(K_{1} \cup K_{s}\right)$ for $r, s \geq 1$.

Since there is no polynomial time algorithm which can be used to determine the metric dimension of any graph, many researchers consider this problem for some particular classes of graphs. Some classes of graph whose metric dimension have been known are cycles [6], trees [5, 8, 10], stars [5, 8, 10], wheels [2, 3, 15], complete multipartite [5, 14], unicylic graphs [12], Cayley graphs [7], and regular graphs $[1]$.

Determining a relation, in terms of metric dimension, between the origin graph and the resulting graph under a graph operation is also interesting to be considered. Some results on joint product graph have been proved in $[2,4,3,15]$. Caceres et. al. [3], Khuler et. al. [10], Melter [11], and Saputro et. al. [14] 
showed the metric dimension of some graphs which obtained from the cartesian product between two or more graphs. Some graphs which constructed from the corona product between two graphs, have been investigated in $[9,18]$. The metric dimension of the composition product graphs have been studied in [13].

In the previous result [13], we proved the general bounds of the metric dimension of a composition product $G[H]$ of a connected graphs $G$ and $H$. We also show that the bounds are tight. In this paper, we determine a general bound of the metric dimension of a composition product of any connected graph $G$ and a star. We can show that the upper bound of a composition product of any graph $G$ and a star is less than the upper bound of $G[H]$. We also show that the bound is sharp.

\section{Main Results}

The composition product of graph $G$ and $H$, denoted by $G[H]$, is the graph with vertex set $V(G) \times V(H)=\{(a, v) \mid a \in V(G), v \in V(H)\}$, where $(a, v)$ adjacent with $(b, w)$ whenever $a b \in E(G)$, or $a=b$ and $v w \in E(H)$. For any vertex $a \in V(G)$, we define $H(a)=\{(a, v) \mid v \in V(H)\}$, and for any vertex $b \in V(H)$, we define $G(b)=\{(v, b) \mid v \in V(G)\}$. For example, let $G \cong P_{3}$ with $V(G)=\{a, b, c\}$, and $H \cong S_{3}$ with $V(H)=\{w, x, y, z\}$. The illustration of $G[H]$ can be seen in Figure 1.

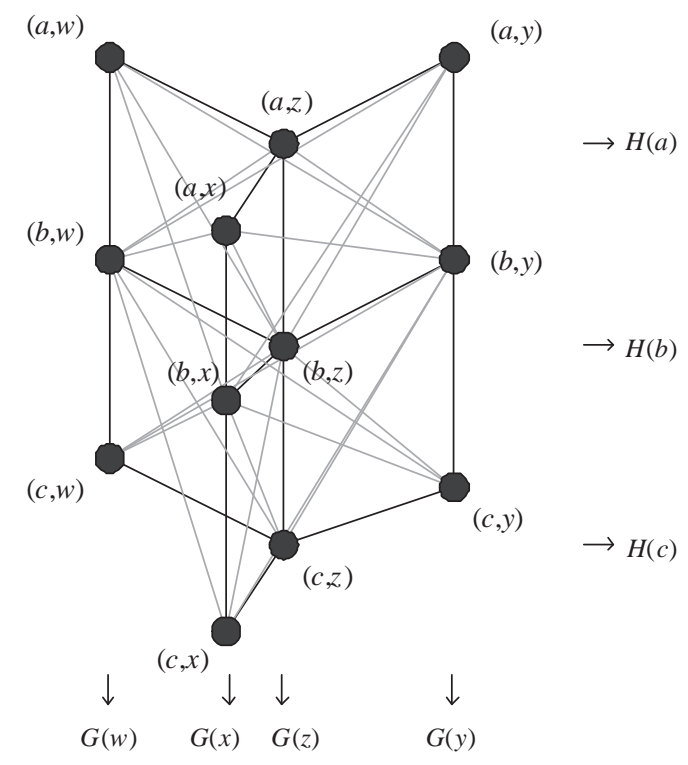

Figure 1. The composition product of $P_{3}$ and $S_{3}$ 
Saputro et. al. [13] have proved the general bounds of $\beta(G[H])$ for any connected graphs $G$ and $H$. They also show that the bounds are tight.

Theorem 2.1. [13] Let $G$ and $H$ be connected graphs with $|V(G)| \geq 1$ and $|V(H)| \geq$ 2. If $|V(G)|=n$, then $n \cdot \beta(H) \leq \beta(G[H]) \leq n \cdot \beta\left(H+K_{1}\right)+(n-2)$.

Now, for $m \geq 3$, we consider $H \cong S_{m}$, a star with $m+1$ vertices. We show that we can reduce the general bounds in Theorem 2.1 above, for $H$ is a star.

By definition of $G[H]$, for $a, b \in V(G)$ and $a \neq b$, every two different vertices $x, y \in H(a)$ satisfy $d_{G[H]}(x, z)=d_{G[H]}(y, z)$ whenever $z \in H(b)$. Therefore, there exist $S_{a} \subseteq H(a)$ such that every two distinct vertices $x, y \in H(a)$ satisfies $r\left(x \mid S_{a}\right) \neq r\left(y \mid S_{a}\right)$.

Lemma 2.2. [13] Let $G$ and $H$ be connected graphs with $|V(G)| \geq 1$ and $|V(H)| \geq$ 2. For any vertex $a \in V(G)$, let $H(a)=\{(a, v) \mid v \in V(H)\}$ be the subset of $V(G[H])$. Let $W$ be a basis of $G[H]$. If $S_{a}=W \cap H(a)$, then $S_{a} \neq \varnothing$. Moreover, if $B$ is a basis of $H$, then $\left|S_{a}\right| \geq|B|$.

Considering Lemma 2.2 and $H \cong S_{m}$, then $\beta(G[H])$ is equal to the lower bound of Theorem 2.1.

Next, we consider a joint graph $H+K_{1}$ where $H \cong S_{m}$. A joint graph of $G$ and $H$, denoted by $G+H$, is a graph with $V(G+H)=V(G) \cup V(H)$ and $E(G+H)=E(G) \cup E(H) \cup\{x y \mid x \in V(G), y \in V(H)\}$. The following lemma show the metric dimension of $H+K_{1}$.

Lemma 2.3. For $m \geq 3$, let $H$ be a star $S_{m}$ with $m+1$ vertices. Then $\beta\left(H+K_{1}\right)=$ $m$.

Proof. Let $V\left(H+K_{1}\right)=\{u, v\} \cup\left\{s_{i} \mid 1 \leq i \leq m\right\}$ and $E(G)=\{u v\} \cup\left\{u s_{i}, v s_{i} \mid 1 \leq\right.$ $i \leq m\}$.

Let $W=\{u\} \cup\left\{s_{i} \mid 1 \leq i \leq m-1\right\}$. Since $v s_{1} \in E(G)$ but $s_{m} s_{1} \notin E(G)$, we obtain $r(v \mid W) \neq r\left(s_{m} \mid W\right)$. Therefore, $W$ is a resolving set of $H+K_{1}$.

Now, suppose that $\beta\left(H+K_{1}\right) \leq m-1$. Let $S$ be a basis of $H+K_{1}$. Then we have two cases of $S$ as follows.

(1) $u, v \notin S$

Since $u z, v z \in E(G)$ for $z \in V(G \backslash\{u, v\})$, we obtain $r(u \mid S)=r(v \mid S)$, a contradiction.

(2) $s_{p}, s_{q} \notin S$ for $p, q \in\{1,2, \ldots, m\}$ and $p \neq q$

Since $s_{p} a, s_{q} a \in E(G)$ for $a \in\{u, v\}$ and $s_{p} b, s_{q} b \notin E(G)$ for $b \in$ $V\left(G \backslash\left\{u, v, s_{p}, s_{q}\right\}\right)$, we obtain $r\left(s_{p} \mid S\right)=r\left(s_{q} \mid S\right)$, a contradiction.

In the theorem below, we show the general upper bounds for $\beta(G[H])$ where $H$ is a star. We can see that the upper bound is less than the general upper bound in Theorem 2.1. 
Theorem 2.4. For $m \geq 3$, let $G$ be a connected graph, and $H \cong S_{m}$ of $m+1$ vertices. If $|V(G)|=n$, then $\beta(G[H]) \leq n \cdot \beta\left(H+K_{1}\right)-1$.

Proof. By Lemma 2.3, $n \cdot \beta\left(H+K_{1}\right)-1=n m-1$. Now, we will show that there exists a resolving set of $n m-1$ vertices.

Let $V(H)=\{u\} \cup\left\{s_{i} \mid 1 \leq i \leq m\right\}$ and $E(H)=\left\{u s_{i} \mid 1 \leq i \leq m\right\}$. Let $P$ be a longest shortest path between two vertices in $G$. Let $b$ be an end point of $P$. We define $W=V(G[H]) \backslash\left(G\left(s_{m}\right) \cup\{(b, u)\}\right)$. We will show that $W$ is a resolving set.

Let $x, y \in V(G)$ and $x \neq y$. We consider two conditions.

(1) $\left(x, s_{m}\right)$ and $\left(y, s_{m}\right)$

If $x y \in E(G)$, then $d_{G[H]}\left(\left(y, s_{m}\right),\left(y, s_{1}\right)\right)=d_{G[H]}\left(\left(x, s_{m}\right),\left(y, s_{1}\right)\right)+1$. Otherwise, $d_{G[H]}\left(\left(x, s_{m}\right),(y, u)\right)=d_{G[H]}\left(\left(y, s_{m}\right),(y, u)\right)+d-1$ where $d=$ $d_{G}(x, y) \geq 2$. Therefore $r\left(\left(x, s_{m}\right) \mid W\right) \neq r\left(\left(y, s_{m}\right) \mid W\right)$.

(2) $\left(x, s_{m}\right)$ and $(b, u)$

Let $c \in V(P)$ and $b c \in E(G)$. Since $(b, u)\left(b, s_{i}\right),(b, u)\left(c, s_{i}\right) \in E(G[H])$ for $1 \leq i \leq m-1$, then $r((b, u) \mid W) \neq r\left(\left(x, s_{m}\right) \mid W\right)$ where $x \in V(G)$. Therefore, $W$ is a resolving set of $G[H]$.

By applying Theorems 2.1 and 2.4 above, we obtain the general bounds of $\beta(G[H])$ with $H \cong S_{m}$ as stated below.

Theorem 2.5. For $n \geq 1$, let $G$ be a connected graph with $n$ vertices. If $H \cong S_{m}$ of $m+1$ vertices where $m \geq 3$, then $n \cdot \beta(H) \leq \beta(G[H]) \leq n \cdot \beta\left(H+K_{1}\right)-1$.

In the next two theorems, we prove that the upper bound and the lower bound in Theorem 2.5 above are the best possible.

Theorem 2.6. For $m \geq 3$, let $G$ be a connected graph, and $H \cong S_{m}$ of $m+1$ vertices. If $|V(G)|=n$, then there exist $G$ such that $\beta(G[H])=n \cdot \beta(H)$.

Proof. For $n \geq 4$, let $G \cong P_{n}$ with $V(G)=\left\{p_{1}, p_{2}, \ldots, p_{n}\right\}$. By Theorem 2.5, we only need to show that $\beta(G[H]) \leq n \cdot \beta(H)$. In $[5,8,10]$, the metric dimension of star of $m+1$ vertices is $m-1$.

Let $V(H)=\{u\} \cup\left\{s_{i} \mid 1 \leq i \leq m\right\}$ and $E(H)=\left\{u s_{i} \mid 1 \leq i \leq m\right\}$. Let $W=V(G[H]) \backslash\left(G(u) \cup G\left(s_{m}\right)\right)$. We will show that $W$ is a resolving set. For $a_{1}, a_{2} \in V(G)$ and $b_{1}, b_{2} \in V(H)$, we consider two possibilities of $\left(a_{1}, b_{1}\right)$ and $\left(a_{2}, b_{2}\right)$ for $b_{1}, b_{2} \in\left\{s_{m}, u\right\}$.

(1) $a_{1}=a_{2}$

Since $\left(a_{1}, u\right)\left(a_{1}, s_{1}\right) \in E(G[H])$ but $\left(a_{1}, s_{m}\right)\left(a_{1}, s_{1}\right) \notin E(G[H])$, then $r\left(\left(a_{1}, u\right) \mid W\right) \neq r\left(\left(a_{1}, s_{m}\right) \mid W\right)$. 
(2) $a_{1} \neq a_{2}$

For $b_{1}, b_{2} \in\left\{s_{m}, u\right\}$, we consider $p=d_{G}\left(a_{1}, a_{2}\right)$ in $G$. Since $n \geq 4$ and $\operatorname{diam}(G)=n-1$, we consider two cases.

(a) $1 \leq p \leq n-2$

Then there exists $a_{3} \in V(G)$ such that $a_{2} a_{3} \in E(G[H])$ and $d_{G}\left(a_{1}, a_{3}\right)=$ $p+1$. Therefore, $d_{G[H]}\left(\left(a_{1}, b_{1}\right),\left(a_{3}, b_{1}\right)\right)=d_{G[H]}\left(\left(a_{1}, b_{1}\right),\left(a_{2}, b_{1}\right)\right)+1$, which implies $r\left(\left(a_{1}, b_{1}\right) \mid W\right) \neq r\left(\left(a_{2}, b_{1}\right) \mid W\right)$.

(b) $p=n-1$

Then there exists $a_{3} \in V(G)$ such that $a_{2} a_{3} \in E(G[H])$ and $d_{G}\left(a_{1}, a_{3}\right)=$ $p-1$. Therefore, $d_{G[H]}\left(\left(a_{1}, b_{1}\right),\left(a_{3}, b_{1}\right)\right) \neq d_{G[H]}\left(\left(a_{1}, b_{1}\right),\left(a_{2}, b_{1}\right)\right)$, which implies $r\left(\left(a_{1}, b_{1}\right) \mid W\right) \neq r\left(\left(a_{2}, b_{1}\right) \mid W\right)$.

Theorem 2.7. For $m \geq 3$, let $G$ be a connected graph, and $H \cong S_{m}$ of $m+1$ vertices. If $|V(G)|=n$, then there exist $G$ such that $\beta(G[H])=n \cdot \beta\left(H+K_{1}\right)-1$.

Proof. For $n \geq 3$, let $G \cong K_{n}$. By Theorem 2.5, we only need to show that $\beta(G[H]) \geq n \cdot \beta\left(H+K_{1}\right)-1$.

Suppose that $\beta(G[H]) \leq n \cdot \beta\left(H+K_{1}\right)-2$ and $W$ is a basis of $G[H]$. By Lemma 2.3, $\beta(G[H]) \leq n \cdot \beta\left(H+K_{1}\right)-2=n m-2$. Note that, $\beta(H)=m-1$ (see $[5,8,10])$. By Lemma 2.2, there exists two distinct vertices $a, b \in V(G)$ such that $H(a)$ contributes $m-1$ vertices to $W$ and so does $H(b)$.

Let $V(H)=\{u\} \cup\left\{s_{i} \mid 1 \leq i \leq m\right\}$ and $E(H)=\left\{u s_{i} \mid 1 \leq i \leq m\right\}$. If there exists two distinct vertices $\left(a, s_{j}\right),\left(a, s_{k}\right) \notin W$, then by definition of $G[H]$, we have $r\left(\left(a, s_{j}\right) \mid W\right)=r\left(\left(a, s_{k}\right) \mid W\right)$, a contradiction. Otherwise, since $(a, u)$ and $(b, u)$ are adjacent to every vertex in $V(G[H]) \backslash\{(a, u),(b, u)\}$, then $r((a, u) \mid W)=r((b, u) \mid W)$, a contradiction.

We also show that there exist graphs $G$ and $H$ such that the metric dimension of $G[H]$ is not equal to both the lower and the upper bounds in Theorem 2.5.

Theorem 2.8. For $m \geq 3$, there exist connected graphs $G$ of order $n \geq 1$ and $H \cong S_{m}$ of order $m+1$ such that $\beta(G[H])=c$ where $n \cdot \beta(H)<c<n \cdot \beta\left(H+K_{1}\right)-1$.

Proof. Let $G \cong P_{3}$ where $V(G)=\left\{p_{1}, p_{2}, p_{3}\right\}$ and $E(G)=\left\{p_{1} p_{2}, p_{2} p_{3}\right\}$, and $H \cong S_{m}$ where $V(H)=\{u\} \cup\left\{s_{i} \mid 1 \leq i \leq m\right\}$ and $E(H)=\left\{u s_{i} \mid 1 \leq i \leq m\right\}$. We will show that $\beta(G[H])=n \cdot \beta(H)+1$. By Lemma 2.3 and the metric dimension of star $S_{m}[5,10]$, we have

$$
\begin{aligned}
n \cdot \beta(H) & <n \cdot \beta(H)+1 \\
& =n(m-1)+1 \\
& =n m-(n-1) \\
& <n m-1 \\
& =n \cdot \beta\left(H+K_{1}\right)-1 .
\end{aligned}
$$


Suppose that $\beta(G[H]) \leq n \cdot \beta(H)$. By Theorem 2.5, we have $\beta(G[H])=$ $n \cdot \beta(H)$. Let $S$ be a basis of $G[H]$. By Lemma 2.2, for every $a \in V(G)$, $H(a)$ contributes $\beta(H)=m-1$ vertices to $W$. If there exists two distinct vertices $\left(a, s_{j}\right),\left(a, s_{k}\right) \notin S$, then by definition of $G[H]$, we have $r\left(\left(a, s_{j}\right) \mid S\right)=$ $r\left(\left(a, s_{k}\right) \mid S\right)$, a contradiction. Otherwise, we consider $\left(p_{1}, s_{j}\right),\left(p_{3}, s_{k}\right) \notin S$ where $j, k \in\{1,2, \ldots, m\}$. Since $d_{G[H]}\left(\left(p_{1}, s_{j}\right), v\right)=2=d_{G[H]}\left(\left(p_{3}, s_{k}\right), v\right)$ for $v \in$ $S \cap\left(H\left(p_{1}\right) \cup H\left(p_{3}\right)\right)$, and $d_{G[H]}\left(\left(p_{1}, s_{j}\right), y\right)=1=d_{G[H]}\left(\left(p_{3}, s_{k}\right), y\right)$ for $y \in S \cap H\left(p_{2}\right)$, we obtain $r\left(\left(p_{1}, s_{j}\right) \mid S\right)=r\left(\left(p_{3}, s_{k}\right) \mid S\right)$, a contradiction.

Now, we define $W=G\left(s_{1}\right) \cup G\left(s_{2}\right) \cup \ldots \cup G\left(s_{m-1}\right) \cup\left\{\left(p_{1}, s_{m}\right)\right\}$. We will show that $W$ is a resolving set.

For $a_{1}, a_{2} \in V(G)$ and $b_{1}, b_{2} \in V(H)$, we consider three possibilities of $\left(a_{1}, b_{1}\right)$ and $\left(a_{2}, b_{2}\right)$ for $b_{1}, b_{2} \in\left\{s_{m}, u\right\}$.

(1) $a_{1}=a_{2}$ where $a_{1} \in\left\{p_{2}, p_{3}\right\}$

Since $\left(a_{1}, u\right)\left(a_{1}, s_{1}\right) \in E(G[H])$ but $\left(a_{1}, s_{m}\right)\left(a_{1}, s_{1}\right) \notin E(G[H])$, then $r\left(\left(a_{1}, u\right) \mid W\right) \neq r\left(\left(a_{1}, s_{m}\right) \mid W\right)$.

(2) $a_{1} \neq a_{2}$

For $b_{1}, b_{2} \in\left\{s_{m}, u\right\}$, we consider $p=d\left(a_{1}, a_{2}\right)$ in $G$. Since $n \geq 4$ and $\operatorname{diam}(G)=n-1$, we consider two cases.

(a) $1 \leq p \leq n-2$

Then there exists $a_{3} \in V(G)$ such that $a_{2} a_{3} \in E(G[H])$ and $d_{G}\left(a_{1}, a_{3}\right)=$ $p+1$. Therefore, $d_{G[H]}\left(\left(a_{1}, b_{1}\right),\left(a_{3}, b_{1}\right)\right)=d_{G[H]}\left(\left(a_{1}, b_{1}\right),\left(a_{2}, b_{1}\right)\right)+1$, which implies $r\left(\left(a_{1}, b_{1}\right) \mid W\right) \neq r\left(\left(a_{2}, b_{1}\right) \mid W\right)$.

(b) $p=n-1$

Then there exists $a_{3} \in V(G)$ such that $a_{2} a_{3} \in E(G[H])$ and $d_{G}\left(a_{1}, a_{3}\right)=$ $p-1$. Therefore, $d_{G[H]}\left(\left(a_{1}, b_{1}\right),\left(a_{3}, b_{1}\right)\right) \neq d_{G[H]}\left(\left(a_{1}, b_{1}\right),\left(a_{2}, b_{1}\right)\right)$, which implies $r\left(\left(a_{1}, b_{1}\right) \mid W\right) \neq r\left(\left(a_{2}, b_{1}\right) \mid W\right)$.

An interesting question is whether all the values between the lower and the upper bounds are achievable, as stated in the following problem.

Problem 2.9. Let $H$ be a star $S_{m}$ of order $m+1$. For every integer $c$ with $n \cdot \beta(H)<c<n \cdot \beta\left(H+K_{1}\right)-1$, does there exist a graph $G$ of order $n$ such that $\beta(G[H])=c$ ?

Acknowledgement The authors are thankful to the anonymous referee for some comments that helped to improve the presentation of the manuscript. 


\section{References}

[1] M. Bača, E.T. Baskoro, A.N.M. Salman, D. Suprijanto, and S.W. Saputro, The metric dimension of regular bipartite graphs, Bull. Math. Soc. Sci. Math. Roumanie (N.S.), 54:1 (102) (2011), 15-28.

[2] P.S. Buczkowski, G. Chartrand, C. Poisson, and P. Zhang, On $k$-dimensional graphs and their bases, Period. Math. Hungar., 46:1 (2003), 9-15

[3] J. Caceres, C. Hernando, M. Mora, M.L. Puertas, I.M. Pelayo, C. Seara, and D.R.Wood, On the metric dimension of some families of graphs, Electronic Notes in Discrete Math., 22 (2005), 129-133.

[4] J. Caceres, C. Hernando, M. Mora, M.L. Puertas, I.M. Pelayo, C. Seara, D.R. Wood, On the metric dimension of cartesian products of graphs, SIAM Journal of Discrete Mathematics, 21:2 (2007), 423-441.

[5] G. Chartrand, L. Eroh, M.A. Johnson, and O.R. Oellermann, Resolvability in graphs and the metric dimension of a graph, Discrete Appl. Math., 105 (2000), 99-113.

[6] G. Chartrand, C. Poisson, and P. Zhang, Resolvability and the upper dimension of graphs, Comput. Math. Appl., 39 (2000), 19-28

[7] M. Fehr, S. Gosselin, O.R. Oellermann, The metric dimension of Cayley digraphs, Discrete Math., 306 (2006) 31-41.

[8] F. Harary, and R.A. Melter, On the metric dimension of a graph, Ars Combin., 2 (1976), 191-195.

[9] H. Iswadi, E.T. Baskoro, R. Simanjuntak, A.N.M. Salman, The metric dimension of graph with pendant edges, J. Combin. Math. Combin. Comput., 65 (2008) 139-145.

[10] S. Khuller, B. Raghavachari, and A. Rosenfeld, Landmarks in graphs, Discrete Appl. Math., 70 (1996), 217-229.

[11] R.A. Melter, I. Tomescu, Metric bases in digital geometry, Comput. Vision, Grapichs, Image Process, 25, (1984), 113-121.

[12] C. Poisson, P. Zhang, The metric dimension of unicyclic graphs, J. Combin. Math. Combin. Comput., 40 (2002), 17-32.

[13] S.W. Saputro, H. Assiyatun, R. Simanjuntak, S. Uttunggadewa, E.T. Baskoro, A.N.M. Salman, The metric dimension of the composition product of graphs, revised.

[14] S. W. Saputro, E.T. Baskoro, A.N.M. Salman, D. Suprijanto, The metric dimension of a complete $n$-partite graph and its cartesian product with a path, J. Combin. Math. Combin. Comput., 71 (2009), 283-293.

[15] B. Shanmukha, B. Sooryanarayana, and K.S. Harinath, Metric dimension of wheels, Far East J. Appl. Math, 8:3 (2002) 217-229.

[16] P.J. Slater, Leaves of trees, Proc. 6th Southeastern Conf. on Combinatorics, Graph Theory, and Computing, Vol 14 of Congr. Numer. (1975) 549-559.

[17] P.J. Slater, Dominating and reference sets in a graph, J. Math. Phys. Sci., 22 (1988), 445-455.

[18] I.G. Yero, D. Kuziak, and J.A. Rodriguez-Velázquez, On the metric dimension of corona product graphs, arXiv:1009.2586v2 [math.CO], (2010), 1-13. 